\title{
Plantas medicinais, usos e memória na Aldeia do Cajueiro, Pará
}

Élida Adriany Brito da Silva ${ }^{1}$, Maria Danielle de Souza da Conceição ${ }^{1}$, Maria Antonia Ferreira Gois $^{2}$ (D), Flávia Cristina Araújo Lucas ${ }^{3 *}$ (D)

${ }^{1}$ Universidade do Estado do Pará, Centro de Ciências Sociais e Educação. Tv. Djalma Dutra, 156, Telégrafo, Belém, PA, 66050-540.

${ }^{2}$ Museu Paraense Emílio Goeldi. Av. Gov Magalhães Barata, 376 - São Brás, Belém - PA, 66040-170

${ }^{3}$ Herbário Profa ${ }^{\text {Dra }}$ Marlene Freitas da Silva. Universidade do Estado do Pará, Centro de Ciências Sociais e Educação.

Tv. Djalma Dutra, 156, Telégrafo, Belém - PA, CEP: 66050-540

* Autora para correspondência: copaldoc@yahoo.com.br

Recebido em 20 de maio de 2020.

Aceito em 14 de setembro de 2020.

Publicado em 30 de setembro de 2020.

Resumo - Quintais tradicionais na Amazônia representam fontes de recursos naturais terapêuticos e expressam conhecimentos relacionados a cultura local. Realizou-se um estudo etnobotânico sobre usos e memória com plantas medicinais na Aldeia Indígena do Cajueiro, município de Paragominas, Pará. Os dados foram obtidos por meio de observação não participante e entrevistas semiestruturadas com especialistas locais, selecionados por seleção racional. A partir das entrevistas foi calculado valor de importância das espécies segundo cada especialista. Trabalhou-se com a História Oral para estimular a busca pela memória de uso e os conhecimentos ainda preservados com a medicina tradicional. Identificaram-se 39 espécies, distribuídas em 22 famílias botânicas. As espécies que obtiveram o maior valor de importância foram caju (Anacardium occidentale L.), manga (Mangifera indica L.), seguidas com pariri (Fridericia chica (Bonpl.) L.G.Lohmann), cidreira (Lippia alba (Mill) N. E. Brown.), capim santo (Cymbopogon citratus (DC.) Stapf). As plantas existentes apenas na memória de alguns dos moradores trouxe a tona fragilidades na transmissão de informações bioculturais entre os membros da comunidade. Modificações nas formas de vida, alteração da paisagem e abandono de práticas tradicionais têm prejudicado o compartilhamento de saberes entre especialistas e moradores.

Palavras chave: Conhecimento tradicional. Etnobotânica. Etnofarmacologia.

\section{Medicinal plants, uses and memory in the Village of Cajueiro, Pará}

Abstract - Traditional backyards in the Amazon represent sources of therapeutic natural resources and express knowledge related to local culture. An ethnobotanical study on uses and memory of medicinal plants was carried out in the Aldeia Indígena do Cajueiro, municipality of Paragominas, Pará. The data were obtained through non-participant observation and semi-structured interviews with local specialists, selected by rational selection. From the interviews, the importance value of the species was calculated according to each specialist. Oral History was worked on to stimulate the search for the memory of use and the knowledge preserved with traditional medicine. 39 species were identified, distributed in 22 botanical families. The species that obtained the greatest importance were cashew (Anacardium occidentale L.), mango (Mangifera indica L.), followed by 
pariri (Fridericia chica (Bonpl.) LGLohmann), lemon balm (Lippia alba (Mill) NE Brown). ), capim santo (Cymbopogon citratus (DC.) Stapf). The plants existing only in the memory of some of the residents brought up flaws in the transmission of biocultural information among members of the community. Changes in ways of life, alteration of the landscape and abandonment of traditional practices compromised the sharing of knowledge between specialists and residents.

Keywords: Traditional knowledge. Ethnobotany. Ethnopharmacology.

\section{Plantas medicinales, usos y memoria en la Aldea del Cajueiro, Pará}

Resumen - Los patios traseros tradicionales en Amazonía representan fuentes de recursos naturales terapéuticos y expresan conocimientos relacionados con la cultura local. En la Aldeia Indígena do Cajueiro, municipio de Paragominas, Pará, se realizó un estudio etnobotánico de usos y memoria con plantas medicinales. Estos datos se obtuvieron mediante observación no participante y entrevistas semiestructuradas con especialistas locales, seleccionados mediante selección racional. A partir de las entrevistas, se calculó el valor de importancia de las especies según cada especialista. Se ha trabajado con la Historia Oral para estimular la búsqueda de la memoria de uso y los conocimientos que aún se conservan con la medicina tradicional. Se identificaron 39 especies, distribuidas en 22 familias botánicas. Las especies que obtuvieron mayor importancia fueron el anacardo (Anacardium occidentale L.), mango (Mangifera indica L.), seguido del pariri (Fridericia chica (Bonpl.) LGLohmann), toronjil (Lippia alba (Mill) NE Brown.), capim santo (Cymbopogon citratus (DC.) Stapf). Las plantas existentes sólo en la memoria de algunos de los pobladores plantearon debilidades en la transmisión de información biocultural entre los miembros de la comunidad. Los cambios en las formas de vida, la alteración del paisaje y el abandono de las prácticas tradicionales han dificultado el intercambio de conocimientos entre especialistas y lugareños.

Palabras clave: Conocimiento tradicional, etnobotánica, etnofarmacología.

\section{Introdução}

O papel das plantas medicinais nos processos de saúde-doença-tratamento-cura entre comunidades tradicionais perpassa por questões históricas, culturais e ambientais, onde a maioria destes povos vive e tem relações estreitas entre si. Conforme discutido por Haverroth (2013) praticamente todo cotidiano destas pessoas gira em torno do manejo de recursos naturais e cultivo de plantas, e na Amazônia essa característica é um traço marcante. Esta interação do povo local com a diversidade florística possibilita diversas maneiras de utilização dos recursos vegetais e uma constante troca de saberes a respeito de remédios, alimentação e artesanato (Guarim Neto et al. 2008).

Desde os primórdios da existência humana, os seres humanos buscam na natureza recursos para melhorar suas próprias condições de vida e, fundamentalmente, aumentar as chances de sobrevivência (Giraldi e Hanazaki 2010). Esse aprendizado popular no meio natural esteve atrelado a constante experimentação e troca de elementos biológicos para serem empregados em prol de remédios, alimentação e artesanato, e se mantém até os dias atuais para o benefício das populações (Linhares et al. 2014). Com os povos indígenas, historicamente e culturalmente, sempre houve relações mais próximas com o meio natural, sendo muitas vezes indissociáveis (Haverroth 2010). 
Pesquisas etnobotânicas com plantas medicinais direcionam-se no sentido de valorizar e inventariar informações da flora local, em determinado contexto de cultura, preservando a diversidade vegetal, o manejo e usos tradicionais (Moreira e Guarim Neto 2015). Von Glasenapp e Thornton (2011) ressaltaram que o entendimento da ciência etnobotânica se amplia por um conjunto de outros elementos que se manifestam em crenças e práticas que as sociedades humanas desenvolvem longitudinalmente em relação ao seu ambiente natural, e essas relações representam o conhecimento ecológico local e indígena e, portanto, são também dinâmicos e co-evoluem em conformidade com as mudanças sociais e ecológicas. Nessa perspectiva, povos indígenas somam amplo conhecimento sobre sistemas ecológicos complexos, melhorando e buscando fontes alternativas na proporção que também contribuem para a conservação e aumento da biodiversidade de determinado bioma.

No Brasil, segundo o último censo demográfico do IBGE realizado em 2010, a população indígena totaliza 817.963, destes 39.081 estão distribuídos no estado do Pará (IBGE 2010). Em relação aos direitos reconhecidos pelo Estado aos povos indígenas no Brasil, estes estão expressos na Constituição Federal de 1988, que conta com um capítulo específico (Título VIII, Da Ordem Social, Capítulo VIII, art. 231 e 232). E no Estatuto do Índio (Lei 6.001), promulgado em 1973. A constituição Federal de 1988 foi um marco na conquista e garantia dos direitos dos indígenas do Brasil, enquanto o Estatuto do Índio previa a integração da população indígena à cultura abrangente, a Constituição passou assegurar direitos legais que preservem os costumes, a organização social, as crenças e tradições da população indígena (Curi 2010).

Apesar destes marcos legais serem bem conhecidos a reprodução do modo de vida de populações indígenas tem sido seriamente afetada por processos de mudanças que surgiram desde o encontro com grupos humanos não indígenas, que resultou em grande número de situações de risco: restrição de territórios, processo de aculturação, instalação de unidades de saúde biomédicas, introdução de doenças, novas relações econômicas e sociais, precariedade na alimentação, entre outros. A despeito de todos esses aspectos que afetam as condições básicas de sobrevivência, o uso de plantas, especialmente relacionadas ao restabelecimento da saúde, ainda é expressivo em diversas etnias (Amorozo e Gely 1988; Almeida 2011; Dario 2018; Silva e Nascimento 2019).

A comunidade indígena Cajueiro, situada no município de Paragominas, Pará, Brasil, vivencia uma realidade de distanciamento com certos costumes tradicionais, principalmente entre os mais jovens. Contínuas alterações de suas áreas naturais têm ocorrido em função de situações socioambientais graves que ainda prevalecem na cidade de Paragominas, apresentada midiaticamente como modelo de "município verde". Criação de animais, produção de leite, mineração, além dos cultivos da soja, milho e arroz, são alguns dos processos exploratórios que ameaçam os territórios da sociobiodiversidade. Tais adversidades mudaram o fluxo dos recursos ali presentes como também a manutenção dos repertórios imemoriais voltados para as questões de saúde com as plantas medicinais.

Considerando natureza e cultura com os povos indígenas, e sua reprodução no modo de vida com os recursos vegetais, o presente trabalho teve como objetivo realizar o estudo sobre os usos e memórias com plantas medicinais na comunidade indígena Cajueiro, Paragominas, Pará, frente os cenários atuais da realidade de vida deste grupo. Para tanto, foram formuladas as seguintes perguntas norteadoras: Quais são os cuidados de saúde empregados no enfrentamento de doenças na comunidade? Há uso de plantas medicinais? Quais são as espécies cultivadas e para que categorias de doenças? Frente as alterações socioambientais ocorridas no município, houve mudança nas práticas de tratamento com plantas medicinais, considerando passado e presente? 


\section{Material e métodos}

\section{O ambiente de estudo}

O município de Paragominas está localizado na mesorregião do sudeste paraense, com população estimada em 97.819 habitantes, que tem como principal atividade econômica agropecuária e indústria (IBGE 2010). O clima da região é do tipo Aw (quente e úmido), de acordo com a classificação de Köppen. A precipitação tem média anual de $1743 \mathrm{~mm}$. A temperatura varia entre $23,3^{\circ} \mathrm{C}$ a $27,3^{\circ} \mathrm{C}$ e a umidade relativa do ar possui média anual de $81 \%$ (Silva et al. 2015).

A Aldeia Cajueiro (300'09.02” S, 47²1'11.22” W), localiza-se as margens do rio Uraim e está inserida em uma das seis comunidades indígenas que formam o município, a uma distância de 125 km de Paragominas (Figura 1).

O solo é do tipo arenoso de textura média e graúda e o relevo é plano possuindo apenas pontos de maior elevação do terreno (Valente e Kahwage 2017). É constituída por 56 famílias de agricultores familiares da etnia Tembé (Comunicação Pessoal).

A aldeia é constituída por habitações que se diferenciam em três tipos: pau a pique, construídas com barro e sustentadas por varas de madeira da floresta; madeira, o tipo mais comum, com telhado de palha ubim (palmeira ubim - Geonoma deversa (Poit.) Kunth); e alvenaria. Não há sistema de saneamento básico ou coleta de lixo e os moradores costumam queimar ou enterrar nos quintais.

Figura 1. Mapa de localização da área de estudo. Fonte: Adaptado de PAIXÃO (2010) (Dados do programa de Interculturalidade e Política na Educação Escolar Indígena da Aldeia Teko Haw- Pará, 2010).

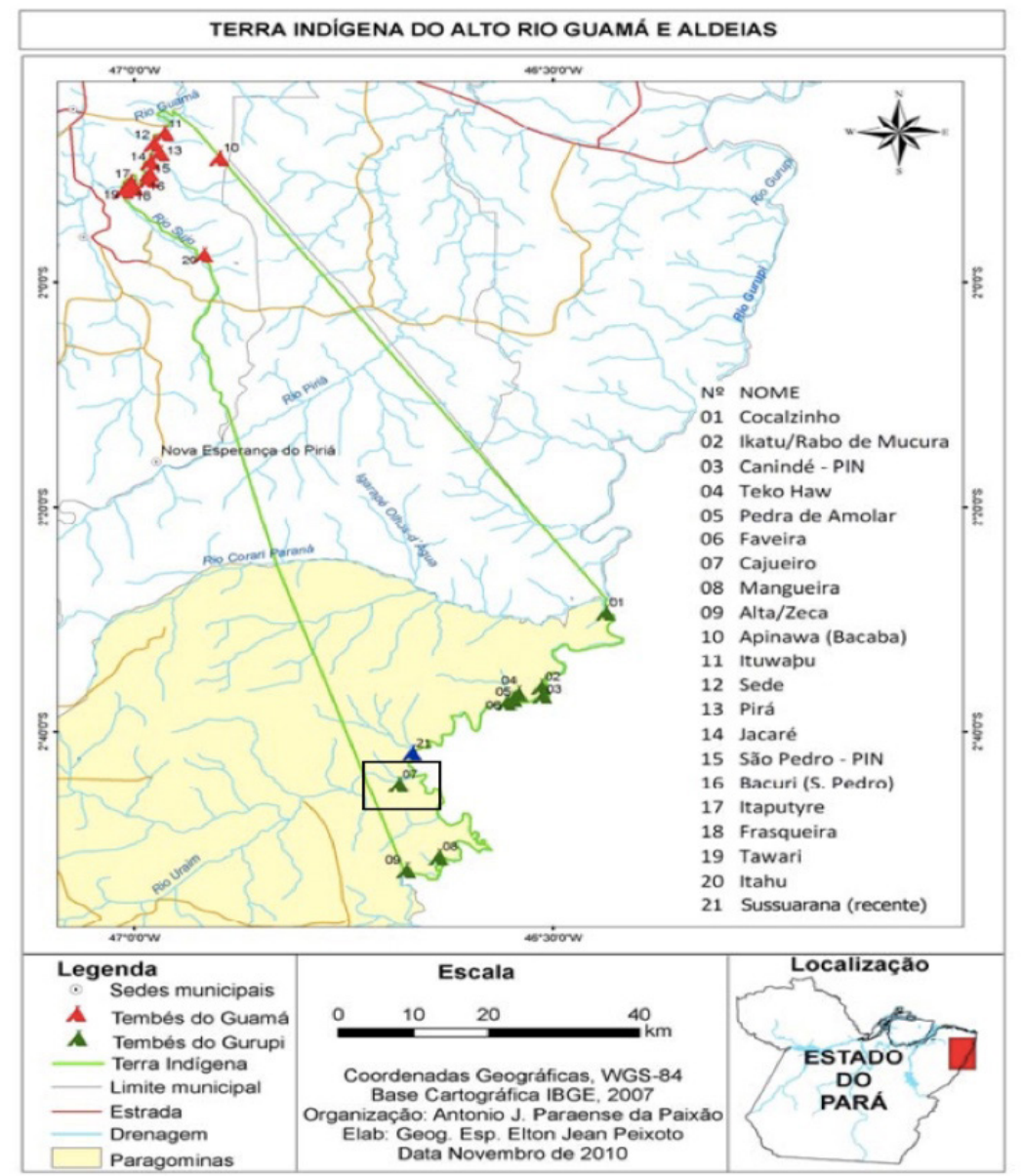


A população é assistida com uma escola de ensino fundamental e médio que atende a 460 crianças e jovens e um posto de saúde de responsabilidade da prefeitura de Paragominas, que conta com uma quantidade reduzida de medicamentos que auxiliam em casos de diarreias, febre, inflamações e dores gerais. Para um atendimento mais especializado os moradores se deslocam à área urbana de Paragominas ou à capital do estado, Belém.

\section{Os Tembé do Gurupi da Aldeia Cajueiro}

Os Tembé do estado do Pará estão divididos em 3 grupos étnicos: Os Tembés Turiwara, os Tembés do Alto Guamá e os Tembés do Gurupi. Os dois últimos habitam duas reservas próximas que formam a Terra Indígena do Alto Rio Guamá, situada no nordeste do Pará, entre a margem direita do rio Guamá e a margem esquerda do rio Gurupi com divisa dos estados do Pará e Maranhão (Dias 2010)

Os indígenas da aldeia Cajueiro pertencem à etnia Tembé do Gurupi, cuja língua nativa é a Tenetehara, mas também falam o português. A aldeia surgiu há aproximadamente 23 anos, a partir de um local estratégico para os índios, onde era possível viver próximo dos rios Uraim e Gurupi e sobreviver da caça e pesca. As características do solo facilitaram a construção das moradias, posicionadas umas próximas às outras, o que também motivou o deslocamento para esse local. Antes de formarem o Cajueiro, os índios habitavam a aldeia Flechal, situada à margem esquerda do rio Gurupi, a uma distância de $2000 \mathrm{~m}$ do Cajueiro.

A principal fonte de renda da comunidade é a agricultura familiar baseada no cultivo de mandioca (Manihot esculenta Crantz), milho (Zea mays L.), feijão da colônia (Vigna unguiculata (L.) Walp.) e arroz (Oryza sativa L.). Os homens são responsáveis pela caça e pesca, enquanto as mulheres pelo artesanato, principalmente colares, pulseiras de frutos e sementes das palmeiras do tucumã (Astrocaryum aculeatum G. Mey) e inajá (Attalea maripa (Aubl.) Mart), além de saias de plumagem de aves e envira (casca da malva).

\section{Autorização da pesquisa}

Antes do início realizou-se visita preliminar para fins de apresentação das intenções do estudo as lideranças e demais membros da aldeia Cajueiro. Após esse momento o representante da comunidade indígena encaminhou o Termo de Consentimento Livre e Esclarecido, elaborado de acordo com a Resolução 466/2012, para apreciação dos comunitários e posterior concordância com a execução do trabalho que resultou na assinatura do termo. Após essa etapa, os termos e o projeto foram cadastrados no Sistema Nacional de Gestão do Patrimônio Genético e do Conhecimento Tradicional Associado (SISGEN), sob o número A2E9804, com o seguinte Objeto do Acesso: Patrimônio Genético e Conhecimento Tradicional Associado, em 12/10/2018, usuário Universidade do Estado do Pará.

\section{Coleta e análise de dados}

As visitas de reconhecimento do local da pesquisa e obtenção de dados ocorreu no período cinco meses consecutivos com estadia de três a cinco dias na comunidade, em cada mês. A seleção dos informantes foi por amostragem não-probabilística (quando não se generaliza para todos os membros do universo amostral) e por seleção racional (Albuquerque et al. 2008), ou seja, fizeram 
parte da pesquisa apenas os indígenas especialistas em plantas medicinais, uma vez que dentre os demais moradores locais, poucos fazem uso e, os que fazem recebem orientação dos especialistas.

A busca pelos especialistas locais ocorreu por meio da técnica bola de neve (Bailey, 1982) que consistiu em solicitar informações a alguns moradores da aldeia acerca das pessoas que possuíam essa expertise, e eram reconhecidas socialmente pelas atividades de cura com plantas medicinais. Para esta abordagem foi perguntado se havia o emprego de plantas para tratamentos de saúde e quais eram as pessoas especialistas nestes assuntos.

As informações foram obtidas a partir das técnicas de observação não participante e entrevistas semiestruturadas (Albuquerque et al. 2010) com seis informantes, sendo três homens e três mulheres com idades entre 23 e 60 anos, os quais foram selecionados aleatoriamente pela própria comunidade com base nas práticas terapêuticas tradicionais que estas pessoas fazem com frequência. Na observação de campo estabeleceu-se o convívio direto com as lideranças e os demais moradores da comunidade, para um melhor conhecimento da realidade local, além de ser possível participar da rotina dos outros comunitários e dialogar a respeito de suas atividades socioeconômicas e identidades étnicas.

As entrevistas semiestruturadas foram organizadas em formulários que continham perguntas abertas e fechadas sobre o perfil socioeconômico e de saúde, buscando identificar as espécies de plantas medicinais, seu uso e aplicações. Após as entrevistas, e para os participantes que se disponibilizavam, foi aplicada a técnica turnê guiada (Albuquerque et al. 2010), que consistiu em caminhadas nas áreas de cultivo para a visualização das plantas citadas. Aplicou-se também o método de História Oral, que permitiu reflexões na trajetória da vida dos indígenas no tempo, em relação à memória sobre as plantas medicinais e que consolidam-se como referência para manutenção dos valores culturais e ambientais da comunidade (Stanisk et al. 2015). As plantas citadas nas lembranças dos antepassados, que eram empregadas em receitas de cura, não foram identificadas com base na nomenclatura científica e permaneceram na designação vernacular. Muitas destas plantas são de difícil localização na comunidade, principalmente as arbóreas (amapá, andiroba, copaíba, maçaranduba e tatajuba), em que há necessidade de longas caminhadas para encontra-las; e outras deixaram de ser cultivadas e/ou empregadas nas receitas de medicamentos. Apesar do alho ser uma etnoespécie de emprego comum, e de fácil obtenção na aldeia, não é de uso frequente na fala dos especialistas.

As etnoespécies inventariadas foram localizadas nos quintais das moradias de cada especialista, e estes espaços foram relatados como os locais onde se encontram seus pequenos sistemas produtivos ou suas florestas. Chagas et al., (2014) analisaram os quintais como áreas produtivas localizadas próximas as residências, que apresentam composição de elementos estruturais e biológicos fortemente influenciados pela tradição cultural dos moradores, pois expressam seus conhecimentos sobre o uso dos recursos naturais. Gonçalves e Lucas (2017) enfatizaram o papel dos quintais como um local de convivência para encontros informais, festas, lazer, curas, cerimônias religiosas dentre outros.

Para a descrição dos seis quintais foi elaborado um croqui, construído segundo Gonçalves e Lucas (2017), com modificações. Desenhou-se um perfil da estrutura e organização dos quintais de cada entrevistado, mostrando de forma ilustrativa os componentes biológicos e não biológicos do local, respeitando as posições e espaçamentos da versão original. Devido à impossibilidade de coleta de amostras botânicas, uma vez que as espécies se encontravam em população reduzida, ou apenas um exemplar cultivado, ou ainda só foram citada pelo uso de memória, foi feito apenas o registro fotográfico das mesmas para posterior identificação no herbário (MFS) Profa. Dra. Marlene Freitas da Silva da Universidade do Estado do Pará. As imagens de campo foram inicialmente denominadas 
com base na nomenclatura popular atribuída pelo morador e, após essa etapa, foram analisadas por comparação com outras bases de dados virtuais: Flora do Brasil 2020 (www.floradobrasil.jbrj.gov. br/), Missouri Botanical Garden - MOBOT (www.tropicos.org/), The Plant List (www.theplantlist. org/). As identificações também foram acompanhadas por um parataxonomista do Museu Paraense Emílio Goeldi, Senhor Carlos Alberto Santos da Silva.

Os usos mencionados para as espécies podem ser classificados em categorias de uso éticas, quando as mesmas são baseadas no ponto de vista de outros, e êmicas, que são denominações da própria cultura local (BYG; Balslev 2001). Para este estudo empregou-se a interpretação de uso êmica. As respostas dos interlocutores foram também avaliadas quanto às espécies mais citadas por eles nas entrevistas e, para estas, foram consultadas outras bibliografias a fim de correlacionar o uso terapêutico validado pelo especialista com os já publicados na academia. Portanto, foram feitas buscas nas bases Scielo, Scopus e Revistas Científicas de América Latina y el Caribe, España y Portugal (Redalyc), sem restrição de ano de publicação.

Calculou-se o Valor de Importância (IVs), metodologia adaptada por Silva et al. (2010), para analisar a proporção de informantes que citaram uma espécie como a mais importante com a seguinte fórmula:

$$
I V_{s}=\frac{n_{i s}}{n}
$$

Em que:

$n_{i s}=$ número de informantes que consideram a espécie mais importante

$\mathrm{n}=$ total de informantes.

\section{Resultados e discussão}

\section{Conhecimento e uso}

Foram identificadas 39 espécies de plantas empregadas como medicinais, pertencentes a 22 famílias botânicas, tendo maior representatividade Fabaceae Lindl., Rutaceae A. Juss, Anacardiaceae R. Brown e Lamiaceae (Quadro 1). O pariri (Fridericia chica (Bonpl.) L.G.Lohmann), manga (Mangifera indica L.), cidreira (Lippia alba (Mill) N. E. Brown.), capim santo (Cymbopogon citratus (DC.) Stapf) e caju (Anacardium occidentale L.) obtiveram maior número de citações.

Quadro 1. Espécies citadas pelos interlocutores na Aldeia Indígena do Cajueiro, Paragominas-Pará. Legendas: QD=Quintal Doméstico; $\mathrm{QF}=\mathrm{Quintal}$ Florestal.

\begin{tabular}{|l|l|l|l|l|l|}
\hline Família/Espécie & Etnoespécie & Indicação & $\begin{array}{l}\text { Parte } \\
\text { usada/ } \\
\text { Localização }\end{array}$ & $\begin{array}{l}\text { Forma de } \\
\text { preparo }\end{array}$ & Citações \\
\hline $\begin{array}{l}\text { AMARANTHACEAE } \\
\text { Dysphania ambrosioides } \\
\text { (L.) Mosyakin \& } \\
\text { Clemants }\end{array}$ & Mastruz & $\begin{array}{l}\text { Anti- } \\
\text { inflamatório/ } \\
\text { Ferimento }\end{array}$ & Folha/QD & Maceração & 1 \\
\hline $\begin{array}{l}\text { AMARYLLIDACEAE } \\
\text { Allium sativum L. }\end{array}$ & Alho & Quebranto/febre & Folha/QD & $\begin{array}{l}\text { Banho/lavagem/ } \\
\text { chá }\end{array}$ & 1 \\
\hline
\end{tabular}




\begin{tabular}{|c|c|c|c|c|c|}
\hline Família/Espécie & Etnoespécie & Indicação & $\begin{array}{l}\text { Parte } \\
\text { usada/ } \\
\text { Localização }\end{array}$ & $\begin{array}{l}\text { Forma de } \\
\text { preparo }\end{array}$ & Citações \\
\hline $\begin{array}{l}\text { ANACARDIACEAE } \\
\text { Anacardium occidentale } \\
\text { L. } \\
\text { Anacardium giganteum } \\
\text { W. Hancock ex Engl } \\
\text { Mangifera indica L }\end{array}$ & $\begin{array}{l}\text { Caju } \\
\text { Cajuí } \\
\text { Manga }\end{array}$ & $\begin{array}{l}\text { Anti- } \\
\text { inflamatório/ } \\
\text { Diarreia } \\
\text { Anti- } \\
\text { inflamatório/ } \\
\text { Diarreia } \\
\text { Estômago/ } \\
\text { diarreia }\end{array}$ & $\begin{array}{l}\text { Folha/casca/ } \\
\text { QD } \\
\text { Casca/QF } \\
\text { Casca/fruto/ } \\
\text { QD }\end{array}$ & $\begin{array}{l}\text { Chá/maceração } \\
\text { Maceração/ } \\
\text { Garrafada } \\
\text { Chá/maceração }\end{array}$ & $\begin{array}{l}3 \\
2 \\
3\end{array}$ \\
\hline $\begin{array}{l}\text { APIACEAE } \\
\text { Eryngium foetidum L. }\end{array}$ & Chicória & Dor de cabeça & Folha/QD & Maceração & 1 \\
\hline $\begin{array}{l}\text { ARECACEAE } \\
\text { Cocos nucifera L. } \\
\text { Euterpe oleracea Mart. }\end{array}$ & $\begin{array}{l}\text { Coco } \\
\text { Açaí }\end{array}$ & $\begin{array}{l}\text { Diarreia } \\
\text { Hepatite B }\end{array}$ & $\begin{array}{l}\text { Fruto/QD } \\
\text { Raiz/QF }\end{array}$ & $\begin{array}{l}\text { Endosperma } \\
\text { sólido } \\
\text { Chá }\end{array}$ & $\begin{array}{l}1 \\
2\end{array}$ \\
\hline $\begin{array}{l}\text { ASTERACEAE } \\
\text { Bidens alba (L.) DC. } \\
\text { Vernonia condensata } \\
\text { Baker }\end{array}$ & $\begin{array}{l}\text { Picão } \\
\text { Boldo }\end{array}$ & $\begin{array}{l}\text { Hepatite B/ } \\
\text { anemia } \\
\text { Malária/ } \\
\text { estômago }\end{array}$ & $\begin{array}{l}\text { Raiz/QD } \\
\text { Folha/QD }\end{array}$ & $\begin{array}{l}\text { Chá } \\
\text { Chá }\end{array}$ & $\begin{array}{l}2 \\
1\end{array}$ \\
\hline $\begin{array}{l}\text { BIGNONIACEAE } \\
\text { Fridericia chica (Bonpl.) } \\
\text { L.G.Lohmann } \\
\text { Tabebuia impetiginosa } \\
\text { (Mart. ex DC.) Standl. }\end{array}$ & $\begin{array}{l}\text { Pariri } \\
\text { Ipê Roxo }\end{array}$ & $\begin{array}{l}\text { Hepatite B/ } \\
\text { anemia } \\
\begin{array}{l}\text { Anti- } \\
\text { inflamatório }\end{array}\end{array}$ & $\begin{array}{l}\text { Folha/QD } \\
\text { Casca/QF }\end{array}$ & $\begin{array}{l}\text { Chá } \\
\text { Garrafada }\end{array}$ & $\begin{array}{l}3 \\
1\end{array}$ \\
\hline $\begin{array}{l}\text { BROMELIACEAE } \\
\text { Ananas comosus L. }\end{array}$ & Abacaxi & $\begin{array}{l}\text { Hemorroida de } \\
\text { sangue }\end{array}$ & Fruto/QD & Suco & 1 \\
\hline $\begin{array}{l}\text { CLUSIACEAE } \\
\text { Platonia insignis Mart. }\end{array}$ & Bacuri & $\begin{array}{l}\text { Anti- } \\
\text { inflamatório }\end{array}$ & Casca/QD & Maceração & 1 \\
\hline $\begin{array}{l}\text { EUPHORBIACEAE } \\
\text { Jatropha curcas L. } \\
\text { Jatropha gossypiifolia L }\end{array}$ & $\begin{array}{l}\text { Pião Branco } \\
\text { Pião roxo }\end{array}$ & $\begin{array}{l}\text { Anti- } \\
\text { inflamatório/ } \\
\text { Sapinho } \\
\text { Dor de cabeça }\end{array}$ & $\begin{array}{l}\text { Folha/casca/ } \\
\text { QD } \\
\text { Folha/QD }\end{array}$ & $\begin{array}{l}\text { Leite } \\
\text { Banho }\end{array}$ & $\begin{array}{l}1 \\
2\end{array}$ \\
\hline $\begin{array}{l}\text { FABACEAE } \\
\text { Stryphnodendron } \\
\text { barbatimam Mart } \\
\text { Copaifera martii Duckei } \\
\text { Dwyer } \\
\text { Bauhinia sp. } \\
\text { Hymenaea courbaril L. } \\
\text { Senna occidentalis (L.) } \\
\text { Link } \\
\text { Dalbergia monetaria L.f. }\end{array}$ & $\begin{array}{l}\text { Barbatimão } \\
\text { Copaíba } \\
\text { Jabuti } \\
\text { Jatobá } \\
\text { Majirioba } \\
\text { Verônica }\end{array}$ & $\begin{array}{l}\text { Anti- } \\
\text { inflamatório } \\
\text { Anti- } \\
\text { inflamatório } \\
\text { ferimento/ Febre } \\
\text { Diarreia } \\
\text { Anti- } \\
\text { inflamatório/ } \\
\text { Hepatite B } \\
\text { Malária } \\
\text { Puxa Nelo }\end{array}$ & $\begin{array}{l}\text { Casca/QF } \\
\text { Óleo/QF } \\
\text { Cipó/QF } \\
\text { Casca/água/ } \\
\text { QF } \\
\text { Raiz/QD } \\
\text { Puxa Nelo }\end{array}$ & $\begin{array}{l}\text { Maceração } \\
\text { Chá } \\
\text { Maceração } \\
\text { Garrafada }\end{array}$ & $\begin{array}{l}1 \\
1 \\
1 \\
1 \\
1 \\
1\end{array}$ \\
\hline $\begin{array}{l}\text { HYPERICACEAE } \\
\text { Hypericum caprifoliatum } \\
\text { Cham. \& Schltdl. }\end{array}$ & Escadinha & Ameba & Cipó/QF & Chá & 1 \\
\hline $\begin{array}{l}\text { IRIDACEAE } \\
\text { Eleutherine bulbosa } \\
\text { (Mill.) Urb }\end{array}$ & $\begin{array}{l}\text { Cebola } \\
\text { coquinho }\end{array}$ & Diarreia & Raiz/QD & Chá & 1 \\
\hline
\end{tabular}




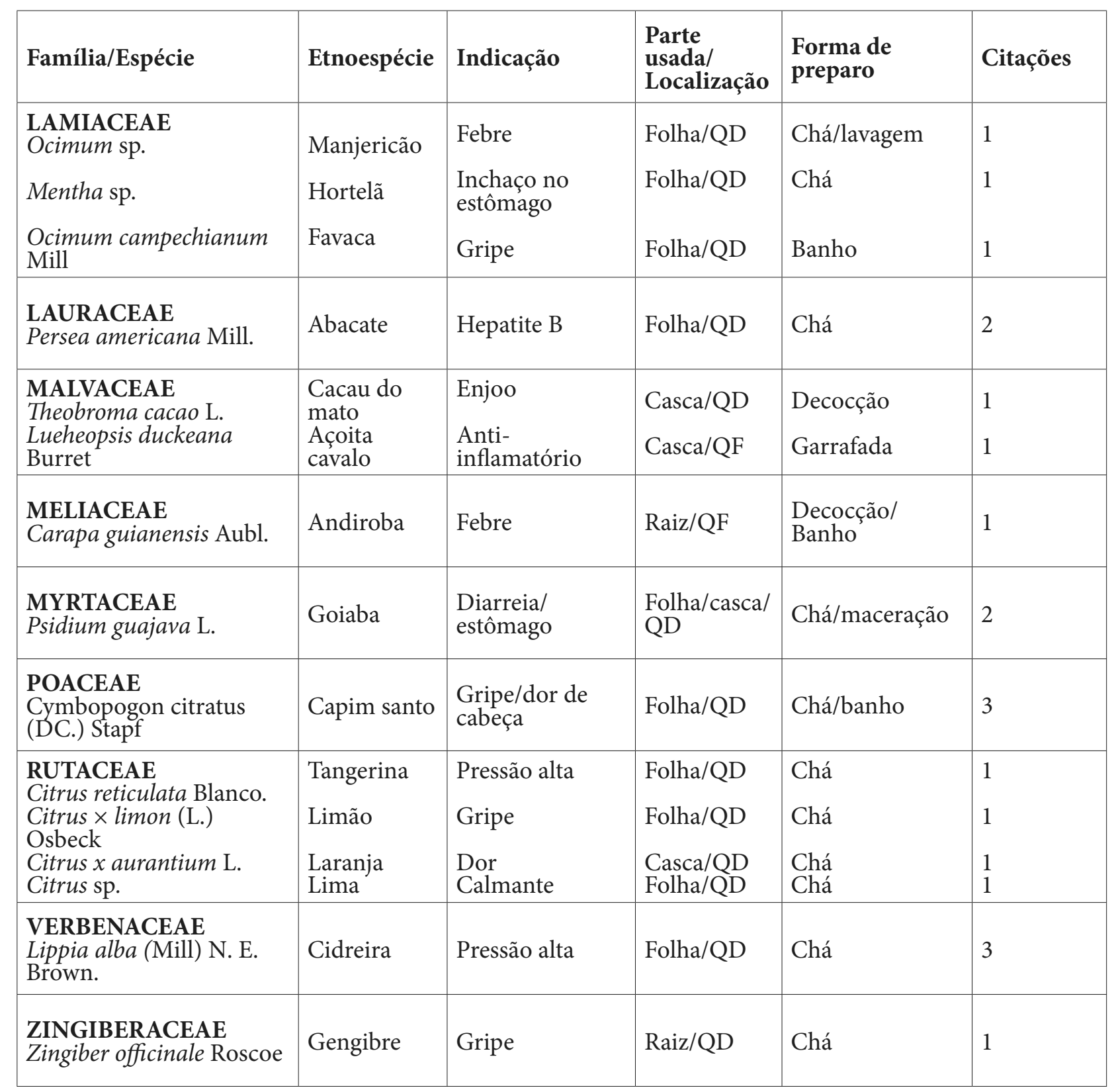

A maior representatividade de Fabaceae e Rutaceae foi evidenciada em outros estudos (Lindenmaier e Putzke 2011; Alves e Povh 2013; Leandro et al. 2017). De acordo com Santos et al. (2017), na Amazônia, Fabaceae é a segunda maior família botânica em número de espécies, superada apenas por Orchidaceae. Na família Rutaceae, espécies dos gêneros Aegle e Citrus, possuem um alto valor medicinal e econômico (Di Stasi e Himura-Lima 2002).

Anacardiaceae obteve grande representatividade também nos estudos de Freitas et al. (2012) e Morais et al. (2005). Di Stasi e Himura-Lima (2002), relataram que essa família, contém espécies produtoras de frutos almejados em todo o território mundial e algumas representam importantes fontes de madeira.

Lamiaceae destacou-se nos trabalhos com comunidades indígenas de Morais et al. (2005), Leite e Marinho (2014) e Gois (2016) com os ribeirinhos de Rio Urubueua de Fátima, Pará, como a família com o maior número de espécies. Por ser rica em óleos essenciais, com propriedades aromáticas e 
medicinais, atua na terapêutica mencionada em diversos estudos (Neto et al. 2014; Moreira e Guarim Neto 2015).

Nas preparações dos remédios caseiros foram usadas diversas partes dos vegetais, com destaque para as folhas, seguida da casca, raiz, fruto, cipó, óleo e exsudato. Este resultado foi também observado nas pesquisas de Cunha e Bortolotto (2011), Pasa (2011) e Vasconcelos e Cunha (2013). No entanto, Santos et al. (2016) e Vasco-dos-Santos et al. (2018) em estudo realizado com a etnia Xipaya, AltamiraPA e com os índios Kantaruré-Batida, NE, respectivamente, demonstraram ser a casca a parte mais empregada, seguida da folha. Isso demonstra que a seleção de determinado órgão da planta, ou a mistura destes, depende em grande parte do conhecimento acumulado e experimentado por um grupo social. Segundo Parthiban et al. (2016) a preferência pelas folhas justifica-se pela facilidade de coleta, por ser a parte mais visível da planta e que sua retirada causa pouco dano ao vegetal, ademais, estão disponíveis em qualquer estação do ano e, por serem ativas fotossinteticamente, há produção de metabólitos secundários (Ghorban 2005).

O chá das folhas por decocção é o modo de preparo mais utilizado, seguido da maceração, banho e garrafada. A preparação por decocção foi encontrada também no método aplicado em comunidades rurais investigadas por Pasa (2011), Leite e Marinho (2014). Em relação aos tipos de receitas, foram relatadas preparações apenas com uma planta (receita simples) e com mais de uma (receita mista). As diferentes espécies de plantas foram combinadas no mesmo preparo para aumentar a eficácia do tratamento de acordo com o informante. Por exemplo, para o tratamento de hepatite B: juntam-se as folhas do abacate (Persea americana Mill) e pariri (Fridericia chica (Bonpl.) L.G.Lohmann) junto com as raízes do açaí (Euterpe oleracea Mart.) e do picão (Bidens alba (L.) DC). Práticas de misturas de plantas adotadas entre índios da Amazônia brasileira foram também observadas nos trabalhos de Frausin et al. (2015) e Vasco-dos-Santos et al. (2018).

$\mathrm{Na}$ opinião de todos os seis especialistas as plantas medicinais são fundamentais no tratamento das doenças mais prevalentes na comunidade, que geralmente são gripes, dores de cabeça e diarreia. As diarreias tornaram-se doenças crônicas, com quadros de melhora e recidiva que, segundo os moradores é ocasionada pela falta de saneamento básico, pois na aldeia não há tratamento de água. Para esta enfermidade costumam ser empregadas sete (07) plantas para tratar os sintomas (Quadro 1). As receitas à base de plantas para tratar diarreia sinalizaram para um problema que se tornou crônico nestes locais, que é a falta de saneamento básico para que as populações indígenas e ribeirinhas tenham o mínimo de qualidade de vida. Gois et al. (2016) e Rocha et al. (2017) em estudo realizado com populações ribeirinhas no estado do Pará comprovaram que as receitas com plantas usadas para tratar distúrbios gastrointestinais foram as mais numerosas e tinham relação direta com à precária qualidade da água.

\section{Plantas medicinais nos quintais das aldeias}

Os quintais simbolizaram coleções de espécies, como repositórios de diversidade vegetal que contribuem no atendimento a saúde desta população. As plantas medicinais encontradas nos quintais se distribuem aleatoriamente tanto nos locais ao redor da casa, quanto no terreno florestal e se destacam tanto por serem ervas, quanto frutíferas medicinais. Dentre as 39 espécies citadas, 27 estão nos quintais peridomésticos e 12 nos quintais florestais (Quadro 1). De acordo com Lunz (2007) e Sales et al. (2008), quintal peridoméstico é o local nos arredores da casa, onde normalmente são 
cultivadas as plantas utilizadas cotidianamente, espécies arbóreas e não arbóreas, como as frutíferas, medicinais e ornamentais. Já o quintal florestal abrange um lugar mais distante das casas, no qual não ocorre um manejo constante de plantar e replantar (Durães et al. 2013).

No quintal estão presentes plantas frutíferas como manga (Mangifera indica L.), murici (Byrsonima euryphylla Pilg.), goiaba (sidium guajava L.), limão (Citrus $\times$ limon (L.) Osbeck), coco (Cocos nucifera L.) e as medicinais: como a cidreira (Lippia alba (Mill) N. E. Brown.) e o capim santo (Cymbopogon citratus). Ao arredor da casa encontra-se a ramanada, local onde são feitas as reuniões, festas e rituais. O retiro é o ambiente onde acontece a produção de farinha, principal forma de renda dos moradores da aldeia. Nas áreas florestais estão inclusas árvores de grande porte como andiroba (Carapa guianensis Aubl.), jatobá (Hymenaea courbaril L.), ipê roxo (Tabebuia impetiginosa (Mart. ex DC.) Standl.) e barbatimão (Stryphnodendron barbatimam Mart.) (Figura 2).

Figura 2. Representação esquemática dos elementos que compõem os quintais peridomésticos e florestais na aldeia do Cajueiro, Paragominas, Pará.

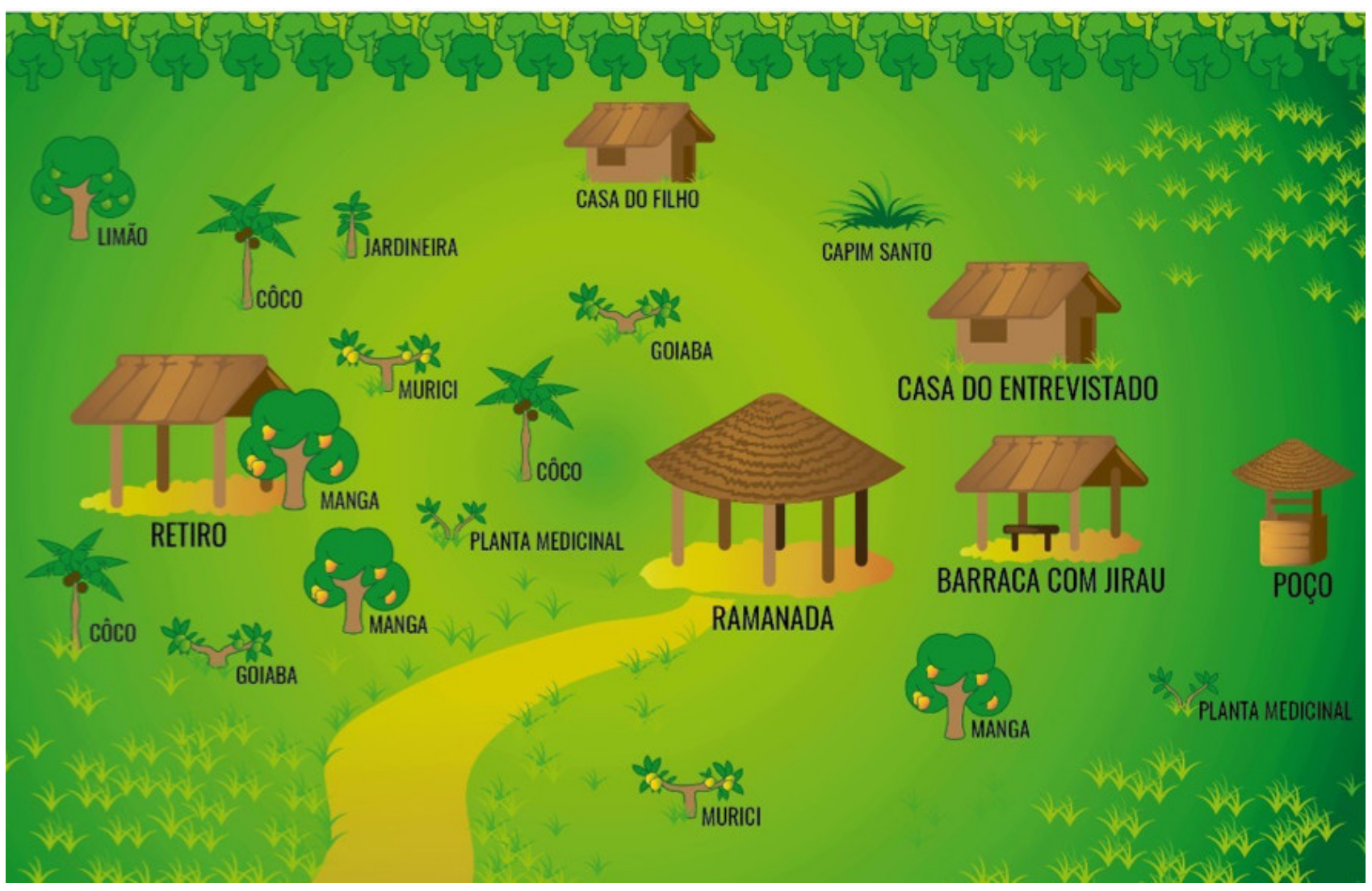

\section{Valor de importância das plantas medicinais}

O valor de importância foi calculado de acordo com as plantas mais relevantes para a população, que totalizaram 5 espécies, ambas com número equivalente de citação e o mesmo número de valor de importância (0,5). Dentre elas Anacardium occidentale L. e Mangifera indica L. foram apontadas como eficazes contra diarreias, que é um problema de saúde marcante na aldeia do Cajueiro. Para as cinco espécies com maior número de citações foram pesquisados e encontrados dados químicos, farmacológicos e estudos clínicos, e desse total quatro têm o uso terapêutico aprovado. 
Na Tabela 2 são apresentadas as cinco espécies, com as informações de dados químicos e farmacológicos encontrados.

Tabela 2. Informações do uso popular e dados científicos das cinco espécies mais citadas pelos Indígenas da Aldeia Cajueiro, Paragominas, Pará.

\begin{tabular}{|c|c|c|c|c|}
\hline $\begin{array}{l}\text { Nome científico } \\
\text { (nome popular) }\end{array}$ & $\begin{array}{l}\text { Forma de } \\
\text { preparo }\end{array}$ & $\begin{array}{l}\text { Usos } \\
\text { mencionados } \\
\text { pelos } \\
\text { especialistas }\end{array}$ & $\begin{array}{l}\text { Usos terapêuticos } \\
\text { aprovados }\end{array}$ & Contraindicações \\
\hline $\begin{array}{l}\text { Anacardium } \\
\text { occidentale L. } \\
\text { (Caju) }\end{array}$ & $\begin{array}{l}\text { 1. Coloca a folha } \\
\text { na água para } \\
\text { ferver. 2. Bate a } \\
\text { casca e coloca na } \\
\text { água. }\end{array}$ & $\begin{array}{l}\text { Diarreia e } \\
\text { Anti- } \\
\text { inflamatório }\end{array}$ & $\begin{array}{l}\text { Ação antimicrobiana } \\
\text { (Silva et al. 2016); } \\
\text { Anti-inflamatório } \\
\text { (Oliveira et al. 2019); } \\
\text { antidiabético (Jaiswal } \\
\text { et al. 2016). }\end{array}$ & $\begin{array}{l}\text { Não deve ser } \\
\text { utilizado por } \\
\text { período superior ao } \\
\text { recomendado, ter } \\
\text { cautela na gravidez } \\
\text { (Bueno et al. 2016). }\end{array}$ \\
\hline $\begin{array}{l}\text { Cymbopogon citratus } \\
\text { (DC.) Stapf } \\
\text { (Capim Santo) }\end{array}$ & $\begin{array}{l}\text { 1. Bate a folha e } \\
\text { coloca na água } \\
\text { para o banho. } 2 . \\
\text { Chá (folha). }\end{array}$ & $\begin{array}{l}\text { Gripe e dor de } \\
\text { cabeça }\end{array}$ & $\begin{array}{l}\text { Anti-inflamatório } \\
\text { e antifúngico } \\
\text { (Boukhatem et al. } \\
\text { 2014); antimicrobiano } \\
\text { (Silva et al. 2018a). }\end{array}$ & - \\
\hline $\begin{array}{l}\text { Fridericia } \\
\text { chica (Bonpl.) } \\
\text { L.G.Lohmann } \\
\text { (Pariri) }\end{array}$ & Chá (folha) & Anemia & $\begin{array}{l}\text { Anti-inflamatório } \\
\text { (Marmitt et al. } \\
\text { 2015); antileshmania } \\
\text { (Rodrigues et al. } \\
\text { 2014) }\end{array}$ & - \\
\hline $\begin{array}{l}\text { Lippia alba (Mill) N. } \\
\text { E. Brown. } \\
\text { (Cidreira) }\end{array}$ & Chá (folha) & Pressão alta & $\begin{array}{l}\text { Ansiolítico e } \\
\text { analgésico (Hatano et } \\
\text { al. 2012; Oliveira et } \\
\text { al. 2016); anti-fúngica } \\
\text { para cepas de } \\
\text { Candida sp. (Cortez et } \\
\text { al. 2015). }\end{array}$ & $\begin{array}{l}\text { Gravidez, devido } \\
\text { à estimulação } \\
\text { do útero e do } \\
\text { fluxo menstrual } \\
\text { (Dermarderosian e } \\
\text { Beutler 2002). }\end{array}$ \\
\hline $\begin{array}{l}\text { Mangifera indica L. } \\
\text { (Manga) }\end{array}$ & $\begin{array}{l}\text { 1. Chá da casca } \\
\text { do fruto; } 2 \text {. Bate a } \\
\text { casca da árvore e } \\
\text { coloca na água. }\end{array}$ & $\begin{array}{l}\text { Diarreia e } \\
\text { estômago }\end{array}$ & $\begin{array}{l}\text { Anti-inflamatória } \\
\text { e antioxidante } \\
\text { (Khumpook et al. } \\
\text { 2019); antitumoral e } \\
\text { antimicrobiana (Raju } \\
\text { et al. 2019). }\end{array}$ & - \\
\hline
\end{tabular}

Verifica-se que de todo o conjunto de plantas no Cajueiro, apenas cinco, um número bem reduzido, são recursos terapêuticos disponíveis, e os mais utilizados. Destas, duas, a manga e o caju, são frutíferas bastante comuns nos quintais de comunidades tradicionais na região Norte, principalmente pelo aproveitamento como alimento e remédio; e por não serem plantas cultivadas, são culturas perenes. O pariri, capim santo e cidreira correspondem a ervas que possuem usos consagrados na literatura etnomédica e foram citados pelos especialistas numa abordagem puramente fitoterápica associadas a sintomas de doenças e agravos de saúde; sem associar efeitos, contra-indicação, rituais, ou qualquer outra restrição.

As doenças de maior ocorrência como hipertensão, anemias e infecções gastroentéricas sinalizaram para investigações de suma importância nas aldeias, que se refere a abordagem da etiologia da enfermidade. O perfil de saúde da comunidade pode variar de acordo com a rotina 
dos moradores e da qualidade do lugar em que vivem. Kumar et al. (2013) reconheceram que as doenças mais comuns, como hipertensão, diabetes e relacionadas ao sistema digestório são causadas por uma combinação de suscetibilidade genética herdada e várias influências ambientais. Os estudos de Kormondy e Brown (2002) alertaram a prevalência elevada de grandes doenças crônicas em populações que alteraram seus modos de vida tradicionais, modernizando-os. Estes autores analisaram ainda a doença hipertensão como resultante de uma série de fatores: idade, sexo, situação socioeconômica, hereditariedade, dieta, peso, gordura maléfica no corpo, estresse e mudanças sociais abruptas.

\section{Memória das plantas medicinais}

A comunidade do Cajueiro tem evidenciado transformações no uso dos recursos naturais ocasionadas por alterações em seus modos de vida, principalmente na perda dos ambientes florestados, que sofrem constantes modificações de paisagens, acarretando mudanças de hábitos com o uso de plantas, alterando dinâmicas extrativistas, dentre outros aspectos que afetam os costumes e valores sociais e de cultura desse povoado. São transformações que provocaram certo distanciamento com práticas tradicionais diversas, como o uso da terra, experimentar receitas com ervas, buscar as plantas na mata, enfim, que vão aos poucos diminuindo o ritmo ou, tornando-se parte apenas da rotina dos especialistas. Os entrevistados afirmaram que muitas espécies vegetais estão se tornando difíceis de encontrar ou desaparecem dos seus locais habituais e, por esse motivo, só existe a memória de uso. Diante deste cenário, realizou-se um resgate memorial das plantas que tiveram grande importância na cura de doenças ao longo da vida dos informantes e que atualmente não são mais procuradas. Foram citadas 21 Etnoespécies (Tabela 3).

Tabela 3. Plantas medicinais citadas com base nas informações de memória dos especialistas da Comunidade Indígena do Cajueiro, Paragominas, Pará. $\left({ }^{\star}\right.$ Etnoespécies mencionadas como "plantas da memória", mas que são utilizadas por outras famílias da comunidade).

\begin{tabular}{llll}
\hline Nome vernacular & Indicação & Parte usada & Manipulação \\
\hline Algodão & Barriga de bebê & Folha & Chá \\
Alho* & Espanta espírito & Folha & Banho \\
Amapá & Limpa por dentro & Leite & \\
Andiroba* & Gripe & Óleo do caule & Decocção \\
Arruda & Dor de cabeça & Folha & Banho \\
Batatão pulga & Anti-inflamatório & Raiz & Maceração \\
Chicória* & Mãe do corpo & Folha & Maceração \\
Copaíba* & Ferimento/derrame & Óleo & \\
Camapú & Malária & Raiz & Decocção \\
Majirioba* & Malária & Raiz & Chá \\
Mamona & Gripe & Semente & Decocção \\
Maçaranduba & Vitamina fortificante & Leite do caule &
\end{tabular}




\begin{tabular}{llll}
\hline Nome vernacular & Indicação & Parte usada & Manipulação \\
\hline Mastruz $^{*}$ & Verme/ferimento no corpo & Folha & Maceração \\
Pariri & Anemia & Folha & Chá \\
Pau-de-remo & Malária & Casca & Maceração \\
Pião roxo & Dor de cabeça & Folha & Banho \\
Picão* & Hepatite B & Raiz & Chá \\
Tatajuba & Diarreia/derrame & Leite do caule & \\
Tiriba & Diarreia & Casca & Maceração \\
Unha de gato & Diarreia & Cipó & Chá \\
Verônica & Anti-inflamatório & Casca & Chá \\
\hline
\end{tabular}

Constatou-se que algumas das plantas e receitas citadas apenas pelo uso de memória da família, (Tabela 3) como Alho, Mastruz, Chicória, Pariri, Andiroba, Copaíba, Majiroba, Pião Roxo, Picão e Verônica, foram encontradas em alguns quintais, e ainda são empregadas. Essa situação é preocupante, pois evidenciou que o compartilhamento dos recursos e saberes associados se encontra fracamente difundido, sendo restrito a cada especialista. Esse perfil comportamental é também resultado de modos mais isolados de convivência entre as famílias, comprometendo a socialização de informações; as famílias costumam ficar mais tempo isoladas em suas casas, ou vão com frequência a Paragominas. Estudo feito por Neto et al. (2014) na comunidade de Sisal, município de Catu apontou a importância da troca e circulação de plantas para a manutenção dos recursos vegetais, visto que muitas das espécies não ocorrem em todos os espaços familiares de cultivo.

É importante considerar que o valor atribuído as plantas medicinais encontradas não se restringe a uma mera descrição de espécies e catalogação etnobotânica, muito pelo contrário, vem trazer uma discussão mais complexa que é a amnésia biocultural, podendo afetar profundamente a medicina tradicional da aldeia. Em última sua análise para este tema Toledo e Barreira-Bassols (2015) enfatizou que se trata de um processo que lentamente ignora sabedorias antigas, desvalorizando-as ou interpretando-as erroneamente, em uma mudança que perpassa pelo cognitivo, social e cultural devido à incapacidade de lembrar de eventos históricos e registros de experiências.

De acordo com uma das interlocutoras, o Batatão de pulga no passado era o primeiro remédio caseiro a ser preparado contra a inflamação, com o poder de cura infalível: “...se tiver uma ferida crônica vai sarar, primeiro remédio que existe..." (B.T, 65 anos). A malária foi outra doença que atingiu a comunidade no passado e costumava-se curar os doentes com a Majirioba: "Majirioba... antigamente no tempo passado, que nós não tinha enfermeiro, não sabia o que era remédio da cidade, curava nós, nós curava malária era com esse remédio aí..." (B.T, 65 anos); "no meu tempo quando eu me entendia, assim com o remédio da Malária, uma vez vovó me curou com a raiz da Majirioba” (C.T, 48 anos).

A lembrança de repertórios tão diversificados e usados pelos pais ou avós, e repassados a alguns filhos foi marcante nos relatos detalhados dos especialistas locais. São informações obtidas em gerações pretéritas, que ao longo do tempo se perderam nas terapêuticas medicinais atuais, na 
medicalização exagerada dos sistemas médicos ocidentais: "aprendi com meus pais, meu pai, minha mãe" (J.T, 59 anos).

Com o registro da História Oral foram colhidos depoimentos de trajetória de grupos sociais que viveram na aldeia, além dos conflitos ambientais e territoriais no município que foram determinantes para entendimento deste momento atual. Lutas por direito e terra e assistenciais, estar próximo da cidade, juntamente com a dificuldade em transmitir conhecimentos as futuras gerações, mudaram as formas de interagir e manejar a natureza, principalmente com os tratamentos medicinais. Buscar os produtos da floresta, da mata, dos rios, do solo, se tornou atividade esporádica; além disso, os recursos também se tornaram escassos.

Nessa linha de raciocínio, o bem estar da saúde e a busca pelo bem viver com plantas que curam, que antes demonstravam forte sentimento de cuidado com o outro, e na perspectiva do associativismo, tem sua permanência ameaçada. As etnoespécies, Algodão, Amapá, Arruda, Batatão de Pulga, Paude-remo, Tiriba, Unha de gato, Mamona, Camapú, Maçaranduba e Tatajuba não se encontram mais na Aldeia, as duas últimas, provavelmente, desapareceram com o desmatamento que continua a ocorrer de forma acelerada nas áreas próximas dali, visto que a madeira dessas espécies tem um grande valor econômico no mercado.

\section{Conclusão}

O estudo demonstrou que o conhecimento sobre plantas medicinais na comunidade Indígena do Cajueiro, resultante das experiências dos seus antepassados e de suas interações atuais, estão centralizados nos repertórios de poucos integrantes da comunidade e este perfil de comportamento foi evidenciado pela frágil rede de transmissão de conhecimentos. A conservação destes repertórios é fundamental no atendimento a saúde desta população, uma vez que as plantas, sejam medicinais ou de consumo alimentício, podem ser encontradas nos quintais dos especialistas, que ainda mantem o hábito de cultivar as espécies. Se o registro desse conhecimento tradicional e oral estivesse melhor distribuído entre os habitantes poderia contribuir para a valorização da memória biocultural da aldeia. Além disso, os dados etnofarmacológicos ratificaram o mérito de cura com os protocolos empregados das receitas ancestrais, comprovando segurança e eficácia; podendo também auxiliar no desenvolvimento de futuras pesquisas em escala industrial.

\section{Agradecimentos}

Os autores agradecem à comunidade indígena do Cajueiro pela disponibilidade em participar da pesquisa e pelo compartilhar seus saberes sobre os vegetais.

Participação dos autores: EABS e MDSC - aplicação de questionário, coleta e organização dos dados e redação do artigo; MAFG - organização das coletas dos dados e aplicação dos questionários e revisão bibliográfica; FCAL - concepção do projeto, coleta e organização dos dados, redação do artigo.

Aprovação ética e licenças: termos e o projeto foram cadastrados no Sistema Nacional de Gestão do Patrimônio Genético e do Conhecimento Tradicional Associado (SISGEN), sob o número A2E9804, com o seguinte Objeto do Acesso: Patrimônio Genético e Conhecimento Tradicional Associado, em 12/10/2018, usuário Universidade do Estado do Pará.

Disponibilidade dos dados: dados não disponíveis. 
Fomento: não houve fonte de fomento.

Conflito de Interesses: não há conflito de interesses.

\section{Referências}

Albuquerque UP, Lucena RFP, Lins-Neto EFM. 2008. Seleção e escolha dos participantes da pesquisa. In: Albuquerque, UP, Lucena, RFP, Cunha, LVFC. Métodos e Técnicas na Pesquisa Etnobotânica. 2 ed. Recife: Editora/NUPEEA. p. 2141.

Albuquerque UP, Lucena RFP, Cunha LVFC. Métodos e técnicas na pesquisa etnobiológica e etnoecológica. (Coleção Estudos e Avanços). 1 ed. Recife.: NUPPEA, 2010.

Almeida MZD. 2011. Plantas medicinais. 3 ed. EDUFBA: Salvador.

Alves MSM, Mendes P. C.; Vieira JDP, Ozela EF, Barbosa WLR, Silva Junior JOC. 2010. Análise farmacognóstica das folhas de Arrabidaea chica (Humb. \& Bonpl.) B. Verlt., Bignoniaceae. Revista Brasileira de Farmacognosia, v. 20, n. 2, p. 215-221.

Alves GSP, Povh JA. 2013. Estudo etnobotânico de plantas medicinais na comunidade de Santa Rita, Ituiutaba - MG. Revista Biotemas, v. 26, n. 3, p. 231-242.

Amaral CND, Guarim Neto G. 2008. Os quintais como espaços de conservação e cultivo de alimentos: um estudo na cidade de Rosário Oeste (Mato Grosso, Brasil). Boletim do Museu Paraense Emílio Goeldi Ciências Humanas, v. 3, n. 3, p. 29-341.

Amorozo MCM, Gély A. 1988. Uso de plantas medicinais por caboclos do Baixo Amazonas, Barcarena, PA, Brasil. Boletim do Museu Paraense Emílio Goeldi, Série Botânica, v. 4, n. 1, p. 47-131.

Araújo BM, Gonçalves RV, Peluzio MDCG, Leite JPV, Chaves GS, Lopes SO, Miranda CC, Queiroz JH de. 2014. Uso do extrato de folhas de Mangifera indica L. e da mangiferina na lesão aterosclerótica em camundongos ApoE-/-. Bioscience Journal, v. 30, n. 6, p. 1873- 1881.

Barbosa WLR, Pinto LDN, Quignard E, Vieira, JMDS, Silva JRJOC, Albuquerque S. 2008. Arrabidaea chica (HBK) Verlot: phytochemical approach, antifungal and trypanocidal activities. Revista Brasileira de Farmacognosia, v. 18, n. 4, p. 544-548.

Bastos TM, Russo HM, Moretti NS, Schenkman S, Marcout L, Gupta MP, Wolfender JL, Queiroz EF, Soares MBP. 2019. Chemical Constituents of Anacardium occidentale as Inhibitors of Trypanosoma cruzi Sirtuins. Molecules, v. 24, n. 3.

Bayala B, Bassole IHN, Maqdasy S, Baron S, Simpore, J, Lobaccaro, JA. 2018. Cymbopogon citratus and Cymbopogon giganteus essential oils have cytotoxic effects on tumor cell cultures. Identification of citral as a new putative antiproliferative molecule. Biochimie, v. 153, p. 162-170.

Boukhatem MN, Ferhat MA, Kameli A, Saidi F, Kebir HT. 2014. Lemon grass (Cymbopogon citratus) essential oil as a potent anti-inflammatory and antifungal drugs. Libyan Journal of Medicine, v. 9.

Brasil. Constituição da República Federativa do Brasil de 1988. Disponível em http://www.planalto.gov.br/ccivil_03/ constituicao/constituicaocompilado.htm (Acesso em 09/01/2018).

Brasil. Lei no 6.001, de 19 de Dezembro de 1973. Dispõe sobre o Estatuto do Índio. Disponível em http://www.planalto. gov.br/ccivil_03/leis/16001.htm (Acessada em 09/01/2018).

Bailey, K. 1982. Methods of social research. The Free Press. New York, EUA.

Bueno MJA. 2016. Manual de plantas medicinais e fitoterápicos utilizados na cicatrização de feridas. $2016.118 \mathrm{f}$. Monografia (Mestrado Profissional) Universidade do Vale do Sapucaí/ UNIVAS, Pouso Alegre. 
Byg A, Balslev H. 2001. Diversity and use of palms in Zahamena, eastern Madagascar. Biodiversity and Conservation, v. 10, n. 6, p. 951-970.

Camargo FF, Souza TR, Costa RB. 2014. Etnoecologia e etnobotânica em ambientes de Cerrado no Estado de Mato Grosso. Interações, v. 15, n. 2, p. 353-360.

Chaves MH, Lopes AMGC, Lopes JAD, Costa DAD, Oliveira CAAD, Costa AF, Brito Júnior FEM. 2010. Fenóis totais, atividade antioxidante e constituintes químicos de extratos de Anacardium occidentale L., Anacardiaceae. Revista brasileira de farmacognosia v. 20, n. 1, p. 106-112.

Chagas JCN, Fraxe TJP, Elias MEA, Castro AP, Vasques MS. 2014. Os sistemas produtivos de plantas medicinais, aromáticas e condimentares nas comunidades São Francisco, Careiro da Várzea e Santa Luzia do Baixio em Iranduba no Amazonas. Revista Brasileira de Agroecologia, 9(1): 111-121.

Chotphruethipong L, Benjakul S, Kijroongrojana K. 2019. Ultrasound assisted extraction of antioxidative phenolics from cashew (Anacardium occidentale L.) leaves. Journal of Food Science and Technology, v. 56, n. 4, p. 1785-1792.

Cortez LER, Yamaguchi MU, Cortez DAG, Pesco DCS. 2015. Avaliação da atividade antifúngica dos óleos essencias de Lippia alba (Mill.) NE Brown (Verbenaceae) e Cymbopogon citratus (DC) Stapf (Poaceae). O Mundo da saúde, v. 39, n. 4, p. 433-440.

Crespo AB. 2010. Recursos Genéticos y Conocimiento Etnofarmacológico Cubanos. Su protección mediante patentes. Boletín Latinoamericano y del Caribe de Plantas Medicinales y Aromáticas, v. 9, n. 3, p. 53-165.

Cunha SA, Bortolotto IM. 2011. Etnobotânica de plantas medicinais no assentamento Monjolinho, município de Anastácio, Mato Grosso do Sul, Brasil. Acta Botanica Brasilica, v. 25, n. 3, p. 685-698.

Curi MV. 2010. Os direitos indígenas e a Constituição Federal. Consilium - Revista Eletrônica de Direito, v. 1, n. 4.

Dario FR. 2018. Uso de plantas da caatinga pelo povo indígena Pankararu no estado de Pernambuco, Brasil. GeoTemas v.8, n.1, p. 60-76.

Dermarderosian A, Beutler JA. 2002. The review of natural products: the most complete source of natural product information. 3 ed. Saint Louis: Facts and Comparisons.

Di Stasi LC, Hiruma-Lima CA. 2002. Plantas medicinais na Amazônia e na Mata Atlântica. 2 ed. São Paulo: Editora UNESP.

Dias C. 2010. O povo Tembé da Terra Indígena do Alto Rio Guamá: construindo vias de desenvolvimento local. 2010. 82 f. Dissertação (Mestrado), Núcleo Meio Ambiente - NUMA, Universidade Federal do Pará, Belém.

Durães AFS, Macedo JD, Pereira KMG, Carvalho LR. 2013. Levantamento Florístico de um quintal florestal no Norte de Minas. In: Ferreira, J.S.; Conceição Junior, V. (Coord.). Anais do $4^{\circ}$ Congresso Nordestino de Engenharia Florestal e $3^{\circ}$ Semana de Engenharia Florestal da Bahia, Vitória da Conquista, Bahia, p. 872-876.

Frausin, G. et al. An ethnobotanical study of anti-malarial plants among indigenous people on the upper Negro River in the Brazilian Amazon. Journal of Ethnopharmacology, v. 174, p. 238-252, 2015.

Freitas AVL, Coelho MDFB, Maia SSS, Azevedo RAB. 2012. Plantas medicinais: um estudo etnobotânico nos quintais do Sítio Cruz, São Miguel, Rio Grande do Norte, Brasil. Revista Brasileira de Biociências, v. 1, n. 1, p. 48-59.

Giraldi M, Hanazaki N. 2010. Uso e conhecimento tradicional de plantas medicinais no Sertão do Ribeirão, Florianópolis, SC, Brasil. Acta Botanica Brasilica, v. 24, n. 2, p. 395-406.

Glassenap, von M, Thornton, TF. 2011. Traditional Ecological Knowledge of Swiss Alpine Farmers and Their Resilience to Socioecological Change. Hum Ecol 39:769-781 DOI 10.1007/s10745-011-9427-6 
Gois MAF, Lucas FCA, Costa JCM da, Moura PHB de, Lobato G de JM. 2016. Etnobotânica de espécies vegetais medicinais no tratamento de transtornos do sistema gastrointestinais. Revista Brasileira de Plantas Medicinais, v.18, n. 2, p. 547-557.

Gonçalves JP, Lucas FCA. 2017. Agrobiodiversidade e etnoconhecimento em quintais de Abaetetuba, Pará, Brasil. Revista brasileira de Biociências, v. 15, n.3, p. 119-134.

Guarim Neto G, Guarim VLM, Macedo M, Nascimento NP. 2008. Flora, vegetação e etnobotânica: conservação de recursos vegetais no pantanal. Gaia Scientia, v. 2, n. 2, p. 41-46.

Ghorbani A. 2005. Studies on pharmaceutical ethno botany in the region of Turk-men Sahra North of Iran (Part 1): general results. Journal Ethnopharmacology, n. 102, v. 1, p. 58-68, Oct.

Hanaa ARM, Sallam YI, El-Leithy AS, Aly SE. 2012. Lemongrass (Cymbopogon citratus) essential oil as affected by drying methods. Annals of Agricultural Science, v. 57, n. 2, p. 113-116.

Hatano VY, Torricelli AS, Giassi ACC, Coslope LA, Viana MB. 2012. Anxiolytic effects of repeated treatment with an essential oil from Lippia alba and (R)-(-)-carvone in the elevated T-maze. Brazilian Journal of Medical and Biological Research, v. 45, p. 238-243.

Haverroth M. 2010. Os desafios da pesquisa etnobotânica entre povos indígenas. In: Silva VA, Almeida ALS, Albuquerque UP. (Orgs.). Etnobiologia e etnoecologia: Pessoas \& Natureza na América Latina. Recife: NUPEEA/SBEE, 2010 (A). p. $133-141$.

IBGE - Instituto Brasileiro de Geografia e Estatística. IBGE CIDADES. 2010. Disponível em https://cidades.ibge.gov. brxtrastemas.phpcodmun=150010\&idtema=1 Acesso em 12/01/2018).

IBGE - Instituto Brasileiro de Geografia e Estatística. 2010. Disponível em: https://www.ibge.gov.br/ https://indigenas. ibge.gov.br/ acesso em 10/05/2020.

Jaiswal YS, Tatke PA, Gabhe SY, Vaidya AB. 2017. Antidiabetic activity of extracts of Anacardium occidentale Linn. leaves on n-streptozotocin diabetic rats. Journal of Traditional Complementary Medicine, v. 7, n. 4, p. 421-427.

Khumpook T, Saenphe S Tragoolpua Y, Saenphet K. 2019. Anti-inflammatory and antioxidant activity of Thai mango (Mangifera indica Linn.) leaf extracts. Comparative Clinical Pathology, v. 28, p. 157-164.

Kormondy EJ, Brown DE. 2002. Ecologia Humana. São Paulo: Atheneu.

Kumar V, Abbas AK, Aster JC. 2013. Robbins Patologia Básica. Rio de Janeiro: Elsevier.

Leandro YAS, Jardem IN, Gavilanes MI. 2017. Uso de plantas medicinais nos cuidados de saúde dos moradores de assentamento no município de Anapu, Pará, Brasil. Biodiversidade, v. 16, n. 2, p. 30-44.

Leite IA, Marinho MDGV. 2014. Levantamento etnobotânico de plantas medicinais em comunidade indígena no município de Baía da Traição-PB. Biodiversidade, v. 13, n. 1, p. 82-105.

Lindenmaier DS, Putzke J. 2011. Estudo etnobotânico em três comunidades Mbya/Guarani na região central do Rio Grande do Sul, Brasil. Revista Caderno de Pesquisa, Série Biologia, v. 23, n.3, p. 6-18.

Linhares JFP, Hortegal EV, Rodrigues MIA, Silva PSS. 2014. Etnobotânica das principais plantas medicinais comercializadas em feiras e mercados de São Luís, Estado do Maranhão, Brasil. Rev. Pan Amaz Saúde, v.5, n.3.

Lunz AMP. 2007. Quintais agroflorestais e o cultivo de espécies frutíferas na Amazônia. Revista Brasileira de Agroecologia, v. 2, n. 2, p. 1-4.

Mamitt DJ, Rempel C, Goettert MI, Silva AC. 2015. Plantas medicinais da RENISUS com potencial anti-inflamatório: revisão sistemática em três bases de dados científicas. Revista Fitos, v. 9, n. 2, p. 129-144. 
Miranda N, Gerola AP, Novello CR, Ueda-Nakamura T, Silva SO, Dias-Filho BP, Hioka N, de Mello JCP, Nakamura CV. 2017. Pheophorbide a, a compound isolated from the leaves of Arrabidaea chica, induces photodynamic inactivation of Trypanosoma cruzi. Photodiagnosis and Photodynamic Therapy, v. 19, p. 256-265.

Morais SM, Dantas JDAP, da Silva ARA, Magalhães EF. 2005. Plantas medicinais usadas pelos índios Tapebas do Ceará. Brazilian Journal of Pharmacognosy, v. 15, n. 2, p. 169-177.

Moreira RPM, Guarim Neto GA. 2015. Flora Medicinal dos Quintais de Tangará da Serra, Mato Grosso, Brasil. Biodiversidade, v. 14, n. 1, p. $63-83$.

Moreno EM, Leal SM, Stashenko EE, García LT. 2018. Induction of programmed cell death in Trypanosoma cruzi by Lippia alba essential oils and their major and synergistic terpenes (citral, limonene and caryophyllene oxide). BMC Complementary and Alternative Medicine, v. 18, n. 1.

Neto FRG, Almeida GSSA, Jesus NG, Fonseca MR. 2014. Estudo Etnobotânico de plantas medicinais utilizadas pela Comunidade do Sisal no município de Catu, Bahia, Brasil. Revista Brasileira de Plantas Medicinais v. 16, n. 4, p. 856865.

Oliveira MGB, Brito RG, Santos PL, Araújo-Filho HG, Quintans JSS, Menezes PP, Serafini MR, Carvalho YMBG, Silva JC, Almeida JRGS, Scotti L, Scotti MT, Shanmugam S, Thangaraj P, Araújo AAS, Quintans-Júnior LJ. 2016. a-Terpineol, a monoterpene alcohol, complexed withb-cyclodextrinexerts antihyperalgesic effect in animal model forfibromyalgia aidedwith docking study. Chemico-Biological Interactions, v. 254, p. 54-62.

Oliveira GT de, Ferreira JMS, Lima WG, Alves LF, Duarte-Almeira JM, Lima LARS 2018. Phytochemical characterisation and bioprospection for antibacterial and antioxidant activities of Lippia alba Brown ex Britton \& Wilson (Verbenaceae). Natural Product Research, v 32, n. 6, p. 723-731.

Oliveira AS, Nascimento JR, Trovão LO, Alves PCS, Maciel MCG, Silva LDM, Marques AA, Santos APSA, Silva LA, Nascimento FRF, Guerra RNM. 2019. The anti-inflammatory activity of Anacardium occidentale L. increases the lifespan of diabetic mice with lethal sepsis. Journal of Ethnopharmacology, 236, p. 345-353.

Paixão AJP. 2010. Interculturalidade e política na educação escolar indígena da aldeia Teko Aaw - Pará. 171 f. Tese (Doutorado) Pontifícia Universidade Católica do Rio de Janeiro, Rio de Janeiro.

Pasa MC. 2011. Saber local e medicina popular: a etnobotânica em Cuiabá, Mato Grosso, Brasil. Boletim do Museu Paraense Emílio Goeldi. Ciências Humanas, v. 6, n. 1, p. 179-196.

Parthiban R, Vijayakumar S, Prabhu S, Yabesh JGEM. 2016. Quantitative traditional knowledge of medicinal plants used to treat livestock diseases from Kudavasal taluk of Thiruvarur district, Tamil Nadu, India. Revista Brasileira de Farmacognosia, n. 26, p. 109-121. DOI: http://dx.doi.org/10.1016/j.bjp.2015.07.016.

Raju NV, Sukumar K, Reddy GB, Pankaj PK, Muralitharan G, Annapareddy S, Sai DT, Chintagunta AD. 2019. Activities of methanolic kernel extract of Mangifera indica L. cultivar Banganapalli. Biomedical \& Pharmacology Journal, v. 12, n. 1, p. 357-362.

Ribeiro SMR, Barbosa LCA, Queiroz JH, Knödler M, Schieber A. 2008. Phenolic compounds and antioxidant capacity of Brazilian mango (Mangifera indica L.) varieties. Food Chemistry, v. 110, n. 3, p. 620-626.

Rodrigues IA, Azevedo MMB, Chaves FCM, Alviano CS, Alviano DS, Vermelho AB. 2014. Arrabidaea chica hexanic extracts induces mitochondrion damage and peptidase inhibition on Leishmania spp. BioMed Research International, v. 2014.

Sales JP, Noda SN, Mendonça MAF, Branco FMC. 2008. A pecuária no sistema de produção familiar na microrregião do alto Solimões, Amazonas. Revista Brasileira de Agroecologia, v. 3, n. 1, p. 20-27.

Santos JX dos, Reis ARS, Matos SA de, Leão FM, Carvalho JC de. 2016. Caracterização etnobotanica de essências florestais com fins medicinais utilizados pela Etnia Xipaya no município de Altamira-PA. Biota Amazônia, v.6, n. 2, p. 1-8. 
Santos AS dos, Silva RL da, Azevedo AL, Oliveira AS de, Silva AE, Silva CA. 2018. Riqueza florística de Fabaceae em diversos ecossistemas do município de Lábrea, estado do Amazonas, Brasil. Cadernos de Agroecologia, v. 12 , n. 1.

Silva AV, Albuquerque UP, Nascimento VT. 2010. Técnicas para análise de dados etnobiológicos. In: ALBUQUERQUE, U.P.; LUCENA, R.F.P.; CUNHA, L.V.F.C. (Org.). Métodos e técnicas na pesquisa etnobiológica e etnoecológica. Recife: NUPPEA, p. 187-206.

Silva AR, Sales A, Veloso CAC. 2015. Influência de sistemas de manejo integrados em um Latossolo Amarelo no desenvolvimento da soja. Acta Iguazu, v. 4, n. 4, p. 50-59.

Silva RA da, Liberio AS, Amaral FMM do, Nascimento FRF do, Torres LMB, Monteiro Neto V, Guerra RNM. 2016. Antimicrobial and antioxidant activity of Anacardium occidentale L. flowers in comparison to bark and leaves extracts. Journal of Biosciences and Medicines, v. 4, p. 87-99.

Silva LE da, Gonçalves MVS, Amaral W do, Quadros DA de, Reis RA, Amaral LDP do, Huergo LF, Garcia B. 2018 a. Chemical composition and antibacterial activity of Cymbopogon citratus and Cymbopogon flexuosus essential oils.

Ciência e Natura, v 40, e2.

Silva RER. da, Morais LP de, Bastos CMS, Pereira-Gonçalves A, Kerntopf MR, Menezes IRA, Leal-Cardoso JH, Barbosa R. 2018b. Vasorelaxant effect of the Lippia alba essential oil and its major constituent, citral, on the contractility of isolated rat aorta. Biomedicine \& Pharmacotherapy, v. 108, p. 792-798.

Silva LS, Nascimento ER. 2019. Resguardo de mulheres da etnia Kambiwá: cuidados culturais. Cadernos de Genero e Diversidade. v.5, n.4, p.1-18. https://portalseer.ufba.br/index.php/cadgendiv.

Soong YY, Barlow PJ. 2004. Antioxidant activity and phenolic content of selected fruit seeds. Food Chemistry, v. 88, n. 3, p. 411-417.

Stanisk A, Floriani N, Silva AAA. 2015. Metodologia da História oral e seu uso em pesquisas etnoecológicas. Terra Plural, v. 9, n. 1, p. 119-134.

Tangpu V, Yadav AK. 2006. Andidiarrhoel activity of Cymbopogon citratus and its main constituent, citral. Phamacologyonline, v. 2, p. 209-298.

Toledo VN, Barreira-Bassols. 2015. A Memória Biocultural: a importância ecológica das sabedorias tradicionais. Expressão Popular. São Paulo, Brasil.

Valente RDM, Kahwage CMC. 2017. Gestão Ambiental e Territorial da Terra Indígena Alto Rio Guamá, Diagnóstico Etnoambiental e Etnozoneamento. Belém: IDEFLOR-BIO.

Vasco-dos-Santos DR, Santos, JV dos, Andrade WM de, Santos-Lima TM dos, Lima LM, Dias-Lima AG, Andrade MJG de, Vannier-dos-Santos MA, Moura GJB de, Nunes E dos S. 2018. Plantas antiparasitárias utilizadas pelos indígenas Kantaruré-Batida (NE-Brasil): Etnobotânica e riscos de erosão do saberes locais. Ambiente \& Sociedade, v.21, p. 1-20.

Vásquez SPF, Mendonça MS, Noda SN. 2014. Etnobotânica de plantas medicinais em comunidades ribeirinhas do Município de Manacapuru, Amazonas, Brasil. Acta Amazônica, v. 44, n. 4, p. 457-472. 